\title{
DISC1 overexpression promotes non-small cell lung cancer cell proliferation
}

\author{
Shuo Wang ${ }^{1,2, *}$, Ying-Ying Chen ${ }^{3,4, *}$, Yu-Peng $\mathrm{Li}^{5}$, Jun Gu${ }^{6}$, Shu-Dong Gu${ }^{4}$, Hai Shi ${ }^{7}$, \\ Xue-Song $\mathrm{Li}^{3}$, Xiao-Ning Lu ${ }^{1,2}$, Xiang $\mathrm{Li}^{8}$, Shuang-Long Zhang ${ }^{1}$, Kang-Jun $\mathrm{Yu}^{1}$, Kun \\ Liu ${ }^{1}$ and Li-Li $\mathbf{J i}^{2}$ \\ ${ }^{1}$ Department of Cardiothoracic Surgery, Affiliated Hospital of Nantong University, Nantong, China \\ ${ }^{2}$ Department of Pathology, Medical School of Nantong University, Nantong, China \\ ${ }^{3}$ Department of Immunology, Medical School of Nantong University, Nantong, China \\ ${ }^{4}$ Department of Oncology, Affiliated Hospital of Nantong University, Nantong, China \\ ${ }^{5}$ Department of Pediatrics, The People's Hospital of Rizhao, Rizhao, China \\ ${ }^{6}$ Department of Respiratory, Affiliated Hospital of Nantong University, Nantong, China \\ ${ }^{7}$ Department of Cardiothoracic Surgery, The Third People's Hospital of Nantong, Nantong, China \\ ${ }^{8}$ Department of Otorhinolaryngology, Maternal and Child Health Care Hospital of Nantong, Nantong, China \\ *These authors have contributed equally to this work \\ Correspondence to: Kun Liu, email: ntliukun@163.com \\ Li-Li Ji, email: kevin08lily@163.com
}

Keywords: non-small cell lung cancer, DISC1, GSK3 $\beta$, $\beta$-catenin, proliferation

Received: February 15, 2017

Accepted: April 27, 2017

Published: May 22, 2017

Copyright: Wang et al. This is an open-access article distributed under the terms of the Creative Commons Attribution License 3.0 (CC BY 3.0), which permits unrestricted use, distribution, and reproduction in any medium, provided the original author and source are credited.

\section{ABSTRACT}

Neuropsychiatric disorder-associated disrupted-in-schizophrenia-1 (DISC1) activates $W n t / \beta$-catenin signaling by inhibiting glycogen synthase kinase 3 beta (GSK3 $\beta$ ) phosphorylation, and may promote neural progenitor cell and pancreatic $\beta$-cell proliferation. The present study found that DISC1 promotes non-small cell lung cancer (NSCLC) cell growth. Western blotting and immunohistochemistry analyses showed that DISC1 was highly expressed in NSCLC cell lines and patient tissues. DISC1 expression was negatively associated with phosphorylated (p-) GSK3 $\beta$, but positively correlated with a more invasive tumor phenotype and predicted poor NSCLC patient prognosis. siRNA-mediated DISC1 silencing increased $p$-GSK3 $\beta$ expression and decreased expression of $\beta$-catenin and Cyclin D1, while DISC1 upregulation produced the opposite results. DISC1 knockdown also reduced NSCLC cell proliferation rates in vitro. These results suggest that DISC1 promotes NSCLC growth, likely through GSK3 $\beta / \beta$-catenin signaling, and that DISC1 may function as an oncogene and novel anti-NSCLC therapeutic target.

\section{INTRODUCTION}

Lung cancer is the most frequently occurring cancer type, and the leading cause of cancer death globally $[1,2]$. Most lung cancer cases are diagnosed at an advanced stage, and approximately $85 \%$ are nonsmall cell lung cancer (NSCLC) [1,3]. NSCLC patient prognosis remains poor; five-year disease-specific mortality rates for stages I-IIIA are $30 \%, 60 \%$, and $75 \%$, respectively [4]. New diagnostic markers are urgently needed to enhance early lung cancer detection and targeted treatment.

Disrupted-in-schizophrenia-1 (DISC1) is a risk gene associated with major mental illnesses, including 
schizophrenia and depression [5]. A balanced $\mathrm{t}[1 ; 11]$ [q42.1; q14.3] translocation that disrupts DISC1 cosegregates with schizophrenia, major depression, and bipolar disorder [6-8]. DISC1 may regulate progenitor cell proliferation and neuronal migration processes $[9,10]$. DISC1 reportedly activates $\mathrm{Wnt} / \beta$ catenin signaling by inhibiting glycogen synthase kinase 3 beta (GSK3 $\beta$ ) kinase activity, thus increasing $\beta$-catenin protein abundance and transcriptional activity [11-13].

The canonical Wnt/ $\beta$-catenin pathway modulates cell proliferation, which is negatively regulated by the $\beta$-catenin destruction complex. GSK3 $\beta$ promotes $\beta$-catenin phosphorylation, resulting in $\beta$-catenin ubiquitylationmediated degradation in the proteasome [14-18]. However, when $\beta$-catenin accumulates in the cytoplasm, it translocates to the nucleus and activates target genes involved in cell proliferation, including Cyclin D1 and c-Myc [19]. Aberrations in this pathway are implicated in the pathogenesis of multiple tumor types, including lung cancer [20-22].

The present study assessed DISC1 expression in human NSCLC cell lines and tumor tissues, and evaluated relationships between DISC1 expression, clinicopathological features, and patient prognosis. We also investigated the role of DISC1 in cancer cell proliferation. We demonstrated that high DISC1 expression promotes NSCLC growth, possibly through GSK3 $\beta / \beta$-catenin signaling.

\section{RESULTS}

\section{DISC1 expression in human NSCLC cell lines and tissues}

Western blotting results showed that DISC1 and PCNA (a cancer cell proliferation marker) levels were higher in NSCLC tissues than in paired adjacent nontumor tissues (Figure 1A-1C), and exhibited similar expression patterns. DISC1 was also highly expressed in the NSCLC cell lines, A549, H1299, and SPCA-1 (Figure 1D-1E).

\section{DISC1 expression is correlated with NSCLC patient clinicopathological parameters}

DISC1 and the Wnt pathway molecules, p-GSK3 $\beta$ (Phosphorylation at Tyr216), $\beta$-catenin, Cyclin D1, and Ki67 , were measured in 140 NSCLC patient tissue samples via immunohistochemical (IHC) analysis. DISC1 and $\beta$-catenin were expressed in the cytoplasm and nucleus, p-GSK $3 \beta$ was prominently expressed in cytoplasm, and Ki-67 was expressed in the nucleus. DISC1, $\beta$-catenin, Cyclin D1, and Ki-67 levels increased from well- to poorly-differentiated NSCLC tissues (Figure 2), and increased with increasing tumor grade. DISC1 and p-GSK3 $\beta$ levels were negatively correlated, indicating that DISC1 might promote NSCLC development through negative regulation of GSK3 $\beta$.

\section{Clinical relevance of DISC1 in NSCLC}

Spearman's rank correlation identified positive associations between DISC1 and $\beta$-catenin $(\mathrm{r}=0.711$, $P<0.01)$, Cyclin D1 $(\mathrm{r}=0.648, P<0.01)$, or $\mathrm{Ki}-$ $67(\mathrm{r}=0.699, P<0.01)$ expression, and a negative correlation between DISC 1 and $\mathrm{p}-\mathrm{GSK} 3 \beta$ expression $(\mathrm{r}=-0.683, P<0.01)$ (Figure 3$)$. DISC1 associations with clinicopathologic variables were evaluated by Pearson $\chi^{2}$ test. DISC1 level was considered high or low according to the cutoff value, for statistical analysis of DISC1 stain, $50 \%$ of malignant cells showing positive stain was used as a cutoff value to distinguish tumors with a low ( $<50 \%$ ) or high ( $\geq 50 \%$ ) level of expression [23]. High DISC1 expression was correlated with smoking status $(P=0.049)$, tumor size $(P=0.013)$, pathology grade $(P<0.001)$, grade $(P=0.020)$, lymph node metastasis $(P=0.032)$, and Ki-67 $(P<0.001), \mathrm{p}-\mathrm{GSK} 3 \beta(P<0.001)$, $\beta$-catenin $(P<0.001)$, and Cyclin D1 expression $(P<0.001)$ (Table 1$)$. There was no correlation with gender $(P=0.800)$, age $(P=0.375)$, clinical stage $(P=0.123)$, or distant metastasis status $(P=0.143)$.

Only $36 \%(26 / 73)$ of the 140 NSCLC patients analyzed survived from the high DISC1 expression group, while $66 \%(44 / 67)$ survived from the low expression group (Table 2), overall survival was calculated from the date of surgery to death or the date of last follow-up. DISC1 $(P<0.01)$, tumor size $(P=0.040)$, pathology grade $(P<0.01)$ were correlated with patient survival status (Table 2 ). Cox's proportional hazards model revealed that DISC1 $(P<0.01)$ and Ki-67 $(P=0.030)$ levels were independent prognostic factors for patient overall survival (Table 3). Kaplan-Meier analysis associated high DISC1 expression with poor patient survival $(P<0.001$; Figure 4$)$.

\section{Effects of DISC1 on NSCLC cell cycle progression}

DISC1 expression was correlated with that of the cell proliferation markers, PCNA and Ki-67, suggesting that DISC1 might regulate NSCLC cell cycle progression. Flow cytometry results showed that A549 cells, which exhibited the highest DISC1 levels of the three tested NSCLC cell lines, were blocked in G0/G1 phase after serum starvation for $72 \mathrm{~h}$. When serum-free medium was replaced with 10\% FBS-supplemented medium, cells were released from G1 phase and entered S phase (Figure 5A). The number of cells in G1 phase decreased from $91.50 \%$ to $52.46 \%$, and those in S phase increased gradually from $5.14 \%$ to $29.78 \%$. Western blotting analysis showed that DISC1, Cyclin D1, and PCNA levels increased after serum supplementation (Figure 5B). 

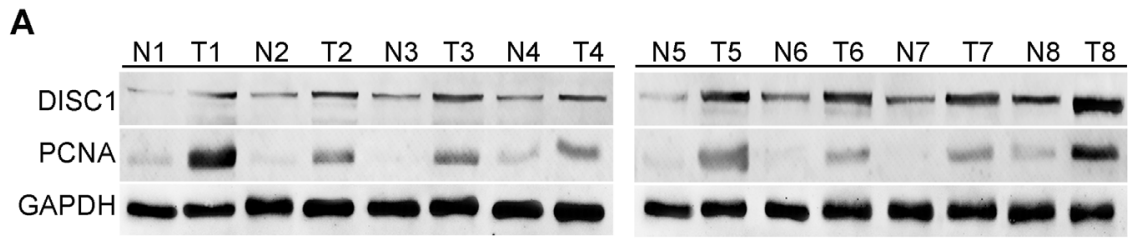

B

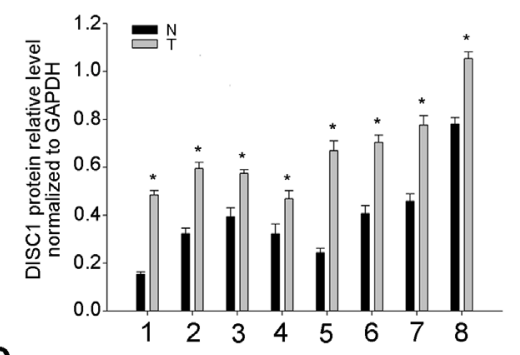

D

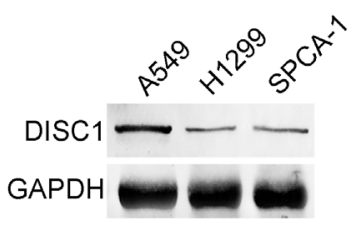

C

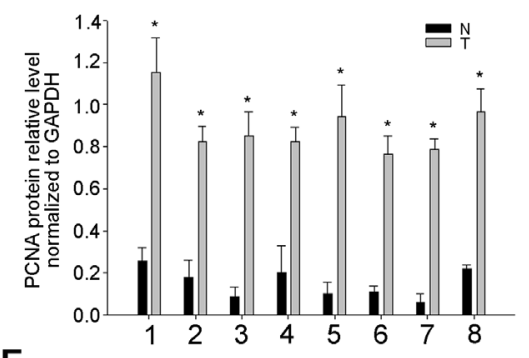

E

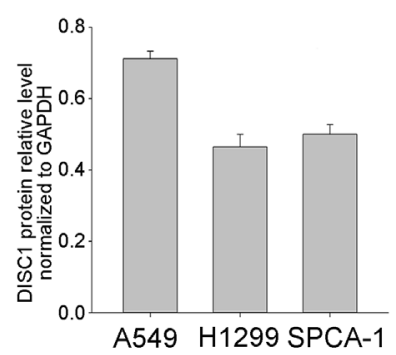

Figure 1: DISC1 expression in human NSCLC tissues and cell lines. DISC1 and PCNA levels in eight paired NSCLC tumor (T) and adjacent non-tumor (N) tissues as shown by western blot analysis (A) GAPDH was used as a loading control. DISC1 (B) and PCNA (C) levels were analyzed in tumor tissues (normalized to GAPDH). ${ }^{*} P<0.05$, compared with adjacent non-tumor tissues. DISC1 expression in NSCLC cell lines (A549, H1299, and SPCA-1) as shown by western blot analysis (D) GAPDH was used as a loading control. DISC1levels were analyzed in NSCLC cell lines (normalized to GAPDH) (E).

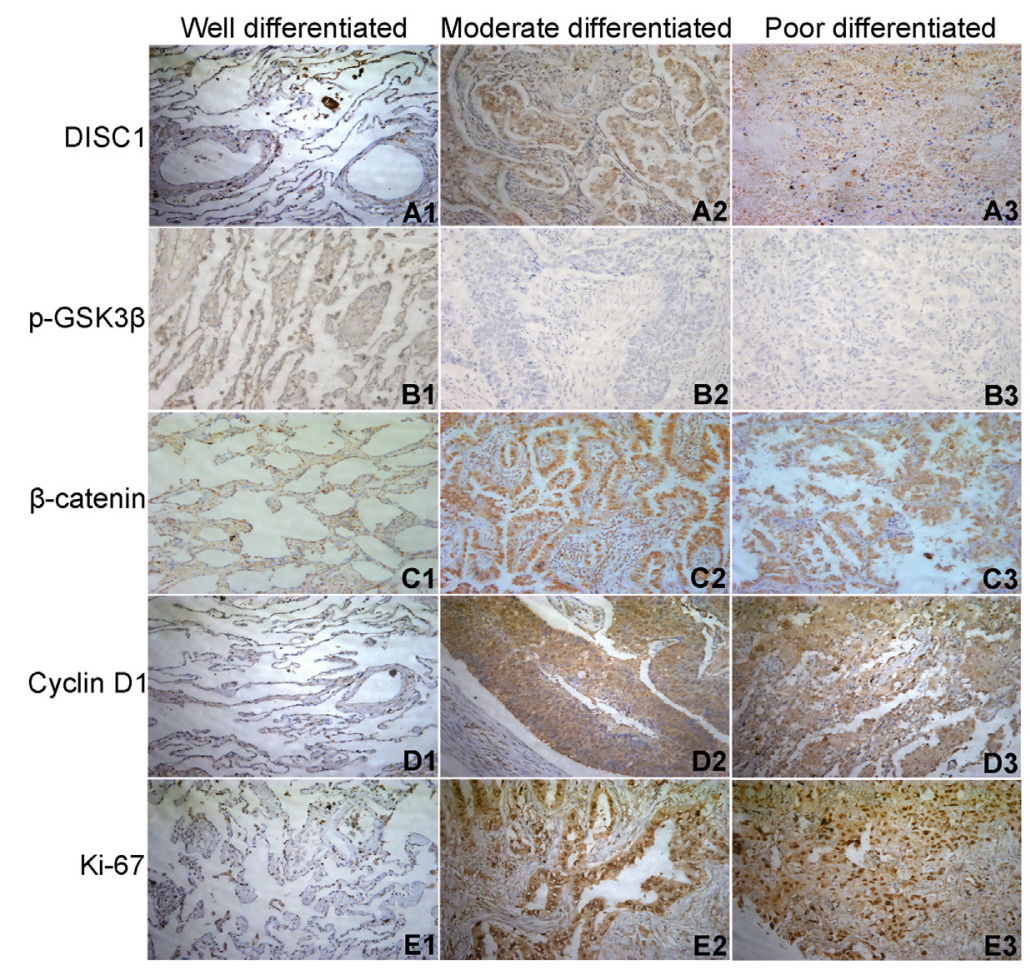

Figure 2: IHC staining of DISC1 (A), p-GSK3 $\beta$ (B), $\beta$-catenin (C), Cyclin D1 (D), and Ki-67 (E) in well- (1), moderately- (2), and poorlydifferentiated (3) NSCLC tissues (200×). 


\section{Effects of DISC1 silencing on NSCLC cell proliferation}

DISC1-targeted siRNAs (DISC1-siRNA1, DISC1siRNA2 and DISC1-siRNA3) and a negative control siRNA (NC-siRNA) were used to assess the impacts of DISC1 on cell proliferation. DISC1 levels decreased in DISC1-silenced A549 cells, as shown by western blotting (Figure 6A-6B). DISC1-siRNA2, which resulted in the greatest level of silencing, was employed in the following experiments. PCNA and Cyclin D1 levels decreased in cells treated with DISC1-siRNA2 (Figure 6C). DISC1 knockdown also reduced NSCLC cell growth rates as shown by CCK-8 assay (Figure 6D) and decreased cell colony formation (Figure 6E-6F).

\section{Correlation between DISC1 and p-GSK3 $\beta$ in NSCLC tissues}

During brain development, DISC1 amino acids 195238 regulate GSK3$\beta / \beta$-catenin/Wnt signaling by inhibiting GSK3 $\beta$ phosphorylation, which in turn reduces $\beta$-catenin phosphorylation and stabilizes $\beta$-catenin [14]. siRNA- mediated DISC1 silencing and a DISC1 over-expression vector (DISC1-Flag) were used to assess the effects of DISC1 on GSK3 $\beta$ in NSCLC. DISC1 knockdown increased p-GSK3 $\beta$ levels, and decreased $\beta$-catenin and Cyclin D1, while DISC1 upregulation produced the opposite results (Figure 7). Thus, we observed a negative correlation between DISC 1 and $\mathrm{p}-\mathrm{GSK} 3 \beta$ in NSCLC cell lines (Figure 8).

\section{DISCUSSION}

Uncontrolled cell proliferation is a major factor in lung cancer development and progression [24]. A more complete understanding of proliferation mechanisms is necessary for the development of novel therapeutics that target uncontrolled cell growth. Our results showed that DISC1 overexpression in NSCLC tissues correlated with patient clinicopathologic factors and predicted poor prognosis, and high DISC1 expression promoted NSCLC cell proliferation. These results indicated that DISC1 might be a novel oncogene, and could promote NSCLC progression.
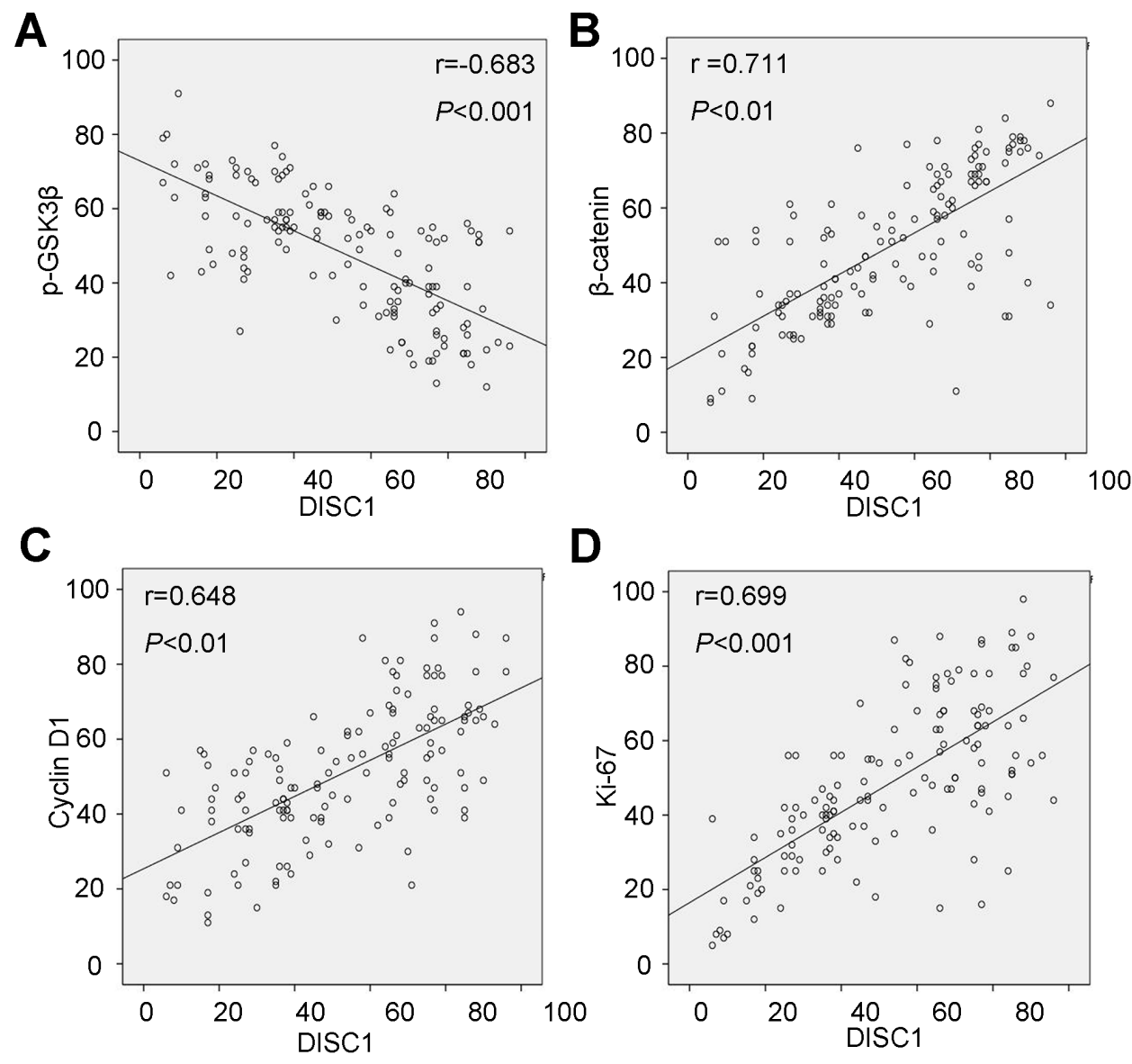

Figure 3: DISC1 expression correlated with that of p-GSK3 $\beta$ (A), $\beta$-catenin (B), Cyclin D1 (C), and Ki-67 (D). 
Table 1: Associations between DISC1 expression and NSCLC patient clinicopathological parameters

\begin{tabular}{|c|c|c|c|c|}
\hline \multirow{2}{*}{$\begin{array}{l}\text { Clinicopathological } \\
\text { parameters }\end{array}$} & \multirow{2}{*}{ Total } & \multicolumn{2}{|c|}{ DISC1 } & \multirow{2}{*}{$P$-value } \\
\hline & & Low $(n=67)$ & $\operatorname{High}(n=73)$ & \\
\hline \multicolumn{5}{|l|}{ Gender } \\
\hline Male & 112 & 53 & 59 & 0.800 \\
\hline Female & 28 & 14 & 14 & \\
\hline \multicolumn{5}{|l|}{ Age } \\
\hline$<60$ & 43 & 23 & 20 & 0.375 \\
\hline$\geq 60$ & 97 & 44 & 53 & \\
\hline \multicolumn{5}{|l|}{ Smoking status } \\
\hline Yes & 57 & 33 & 24 & $0.049 *$ \\
\hline No & 83 & 34 & 49 & \\
\hline \multicolumn{5}{|l|}{ Tumor size $(\mathrm{cm})$} \\
\hline$\leq 3$ & 60 & 36 & 24 & $0.013^{*}$ \\
\hline$>3$ & 80 & 31 & 49 & \\
\hline \multicolumn{5}{|l|}{ Clinical stage (TNM) } \\
\hline $\mathrm{T} 1+\mathrm{T} 2$ & 125 & 57 & 68 & 0.123 \\
\hline $\mathrm{T} 3+\mathrm{T} 4$ & 15 & 10 & 5 & \\
\hline \multicolumn{5}{|l|}{ Pathology grade } \\
\hline Poor & 41 & 27 & 14 & $<0.001^{*}$ \\
\hline Mod & 60 & 31 & 29 & \\
\hline Well & 39 & 9 & 30 & \\
\hline \multicolumn{5}{|l|}{ Grade } \\
\hline $\mathrm{I}+\mathrm{II}$ & 93 & 51 & 42 & $0.020^{*}$ \\
\hline III+IV & 47 & 16 & 31 & \\
\hline \multicolumn{5}{|l|}{$\begin{array}{l}\text { Lymph node } \\
\text { metastasis }\end{array}$} \\
\hline No & 54 & 32 & 22 & $0.032 *$ \\
\hline Yes & 86 & 35 & 51 & \\
\hline \multicolumn{5}{|l|}{$\begin{array}{l}\text { Distant metastasis } \\
\text { status }\end{array}$} \\
\hline M0 & 105 & 54 & 51 & 0.143 \\
\hline M1 & 35 & 13 & 22 & \\
\hline \multicolumn{5}{|l|}{ p-GSK3 $\beta$ expression } \\
\hline Low & 66 & 13 & 53 & $<0.001^{*}$ \\
\hline High & 74 & 54 & 20 & \\
\hline \multicolumn{5}{|l|}{$\beta$-catenin expression } \\
\hline Low & 70 & 53 & 17 & $<0.001^{*}$ \\
\hline High & 70 & 14 & 56 & \\
\hline
\end{tabular}




\begin{tabular}{|c|c|c|c|c|}
\hline \multirow{2}{*}{$\begin{array}{l}\text { Clinicopathological } \\
\text { parameters }\end{array}$} & \multirow{2}{*}{ Total } & \multicolumn{2}{|c|}{ DISC1 } & \multirow{2}{*}{$P$-value } \\
\hline & & Low $(n=67)$ & High $(n=73)$ & \\
\hline \multicolumn{5}{|l|}{ Cyclin D1 expression } \\
\hline Low & 65 & 49 & 16 & $<0.001^{*}$ \\
\hline High & 75 & 18 & 57 & \\
\hline \multicolumn{5}{|l|}{ Ki-67 expression } \\
\hline Low & 78 & 60 & 18 & $<0.001^{*}$ \\
\hline High & 62 & 7 & 55 & \\
\hline
\end{tabular}

${ }^{*} P<0.05$ (Pearson $\chi^{2}$ test) was considered significant.

Table 2: Univariate analysis of NSCLC patient clinicopathological parameters with respect to survival

\begin{tabular}{|c|c|c|c|c|}
\hline \multirow{2}{*}{$\begin{array}{l}\text { Clinicopathological } \\
\text { parameters }\end{array}$} & \multirow{2}{*}{ Total } & \multicolumn{2}{|c|}{ Survival status } & \multirow{2}{*}{$P$-value } \\
\hline & & Died & Alive & \\
\hline \multicolumn{5}{|l|}{ Gender } \\
\hline Male & 112 & 55 & 57 & 0.673 \\
\hline Female & 28 & 15 & 13 & \\
\hline \multicolumn{5}{|l|}{ Age } \\
\hline$<60$ & 43 & 23 & 20 & 0.583 \\
\hline$\geq 60$ & 97 & 47 & 50 & \\
\hline \multicolumn{5}{|l|}{ Smoking status } \\
\hline Yes & 57 & 23 & 34 & 0.058 \\
\hline No & 83 & 47 & 36 & \\
\hline \multicolumn{5}{|l|}{ Tumor size (cm) } \\
\hline$\leq 3$ & 60 & 24 & 36 & $0.040 *$ \\
\hline$>3$ & 80 & 46 & 34 & \\
\hline \multicolumn{5}{|l|}{ Clinical stage (TNM) } \\
\hline $\mathrm{T} 1+\mathrm{T} 2$ & 125 & 63 & 62 & 0.785 \\
\hline $\mathrm{T} 3+\mathrm{T} 4$ & 15 & 7 & 8 & \\
\hline \multicolumn{5}{|l|}{ Pathology grade } \\
\hline Poor & 41 & 12 & 29 & $<0.01^{*}$ \\
\hline Mod & 60 & 27 & 33 & \\
\hline Well & 39 & 31 & 8 & \\
\hline \multicolumn{5}{|l|}{ Grade } \\
\hline $\mathrm{I}+\mathrm{II}$ & 93 & 42 & 51 & 0.107 \\
\hline $\mathrm{III}+\mathrm{IV}$ & 47 & 28 & 18 & \\
\hline
\end{tabular}

(Continued) 


\begin{tabular}{|c|c|c|c|c|}
\hline \multirow{2}{*}{$\begin{array}{l}\text { Clinicopathological } \\
\text { parameters }\end{array}$} & \multirow{2}{*}{ Total } & \multicolumn{2}{|c|}{ Survival status } & \multirow{2}{*}{$P$-valu } \\
\hline & & Died & Alive & \\
\hline \multicolumn{5}{|l|}{$\begin{array}{l}\text { Lymph node } \\
\text { metastasis }\end{array}$} \\
\hline No & 54 & 29 & 25 & 0.487 \\
\hline Yes & 86 & 41 & 45 & \\
\hline \multicolumn{5}{|l|}{$\begin{array}{l}\text { Distant metastasis } \\
\text { status }\end{array}$} \\
\hline M0 & 105 & 54 & 51 & 0.558 \\
\hline M1 & 35 & 16 & 19 & \\
\hline \multicolumn{5}{|l|}{ DISC1 expression } \\
\hline Low & 67 & 23 & 44 & $<0.01 *$ \\
\hline High & 73 & 47 & 26 & \\
\hline \multicolumn{5}{|l|}{ p-GSK3 $\beta$ expression } \\
\hline Low & 66 & 35 & 31 & 0.498 \\
\hline High & 74 & 35 & 39 & \\
\hline \multicolumn{5}{|l|}{$\beta$-catenin expression } \\
\hline Low & 70 & 30 & 40 & 0.091 \\
\hline High & 70 & 40 & 30 & \\
\hline \multicolumn{5}{|l|}{ Cyclin D1 expression } \\
\hline Low & 65 & 32 & 33 & 0.865 \\
\hline High & 75 & 38 & 37 & \\
\hline \multicolumn{5}{|l|}{ Ki-67 expression } \\
\hline Low & 78 & 31 & 47 & $0.006^{*}$ \\
\hline High & 62 & 38 & 23 & \\
\hline
\end{tabular}

$* P<0.05$ (Pearson $\chi^{2}$ test) was considered significant.

Table 3: Cox regression analysis of potential prognostic factors with respect to NSCLC patient survival

\begin{tabular}{lccc}
\hline & Hazard ratio & 95\% confidence interval & $P$-value \\
\hline Tumor size $(\mathrm{cm})$ & 1.446 & $1.000-2.972$ & 0.050 \\
Pathology grade & 1.169 & $0.991-1.978$ & 0.057 \\
DISC1 expression & 2.498 & $1.140-5.798$ & $<0.01^{*}$ \\
Ki-67 expression & 1.625 & $0.810-3.162$ & $0.030^{*}$ \\
\hline
\end{tabular}

$* P<0.05$ (Cox regression analysis) was considered significant.

DISC1 was first associated with a variety of brain disorders, including schizophrenia, mood disorders, and autism [10-12]. DISC1 is an important neural progenitor cell proliferation regulator that positively modulates canonical Wnt signaling by inhibiting GSK3 $\beta$ catalytic activity, which activates $\beta$-catenin [14]. We found that DISC1 was overexpressed in NSCLC patient tissues, and hypothesized that it might promote NSCLC cell proliferation. IHC analyses demonstrated that DISC1 expression in NSCLC patient tissues correlated with 


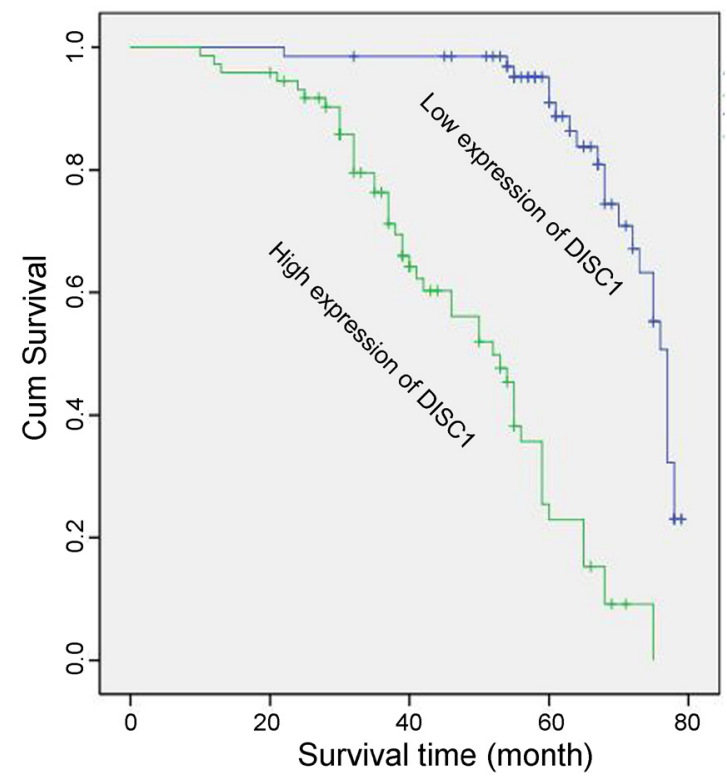

Figure 4: Kaplan-Meier survival analysis of DISC1 expression in NSCLC patients. Cumulative overall NSCLC patient survival rate was associated with high (green line) or low (blue line) DISC1 expression.
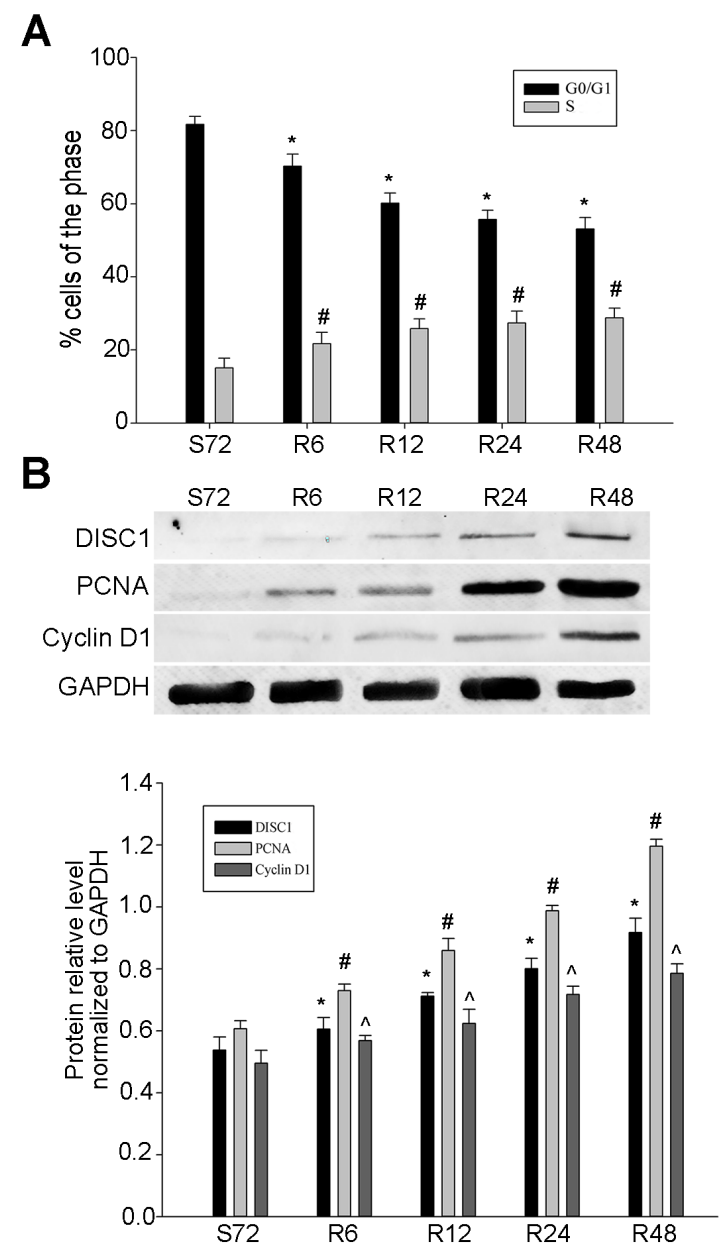

Figure 5: DISC1 promoted NSCLC cell proliferation. A549 cell cycle progress was detected by flow cytometry (A) cells were synchronized at G1 phase after serum starvation for $72 \mathrm{~h}$, and progressed into $\mathrm{S}$ phase with the addition of $10 \% \mathrm{FBS}$-supplemented medium for 6, 12, 24, or 48 h. PCNA and Cyclin D1 were detected by western blotting (B) PCNA and Cyclin D1 levels were analyzed (normalized to GAPDH). *, \#, $\wedge P<0.05$, compared with cells (serum starved for $72 \mathrm{~h}$ ). S: starvation; R: release. 
A
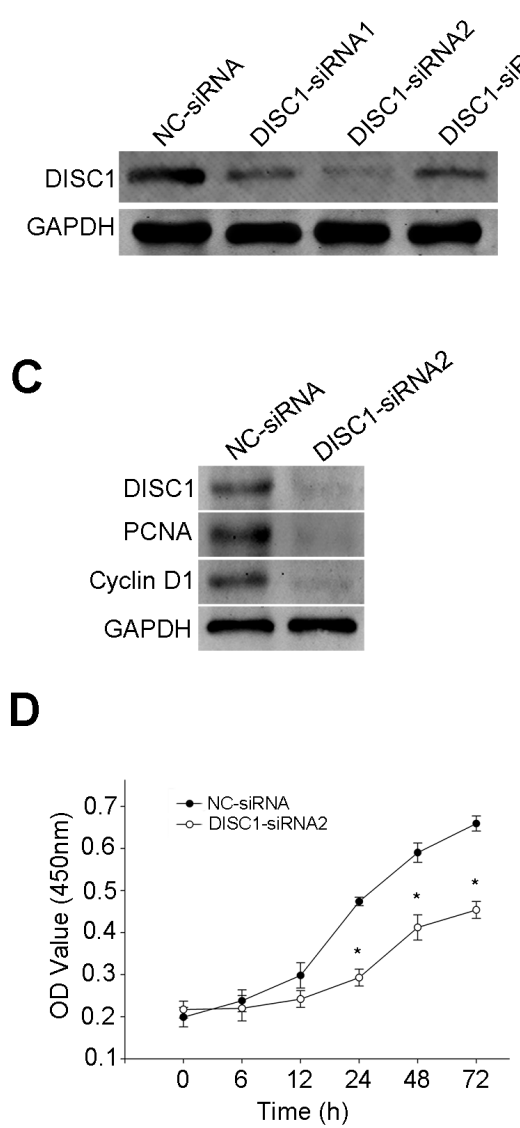

B

$E$
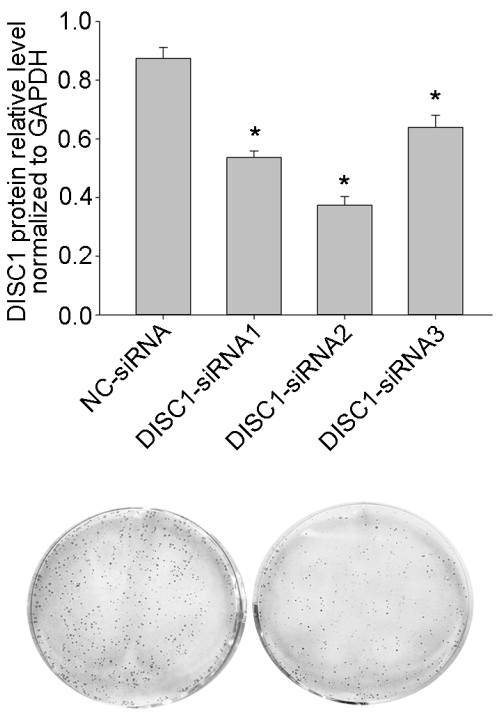

$\mathbf{F}$

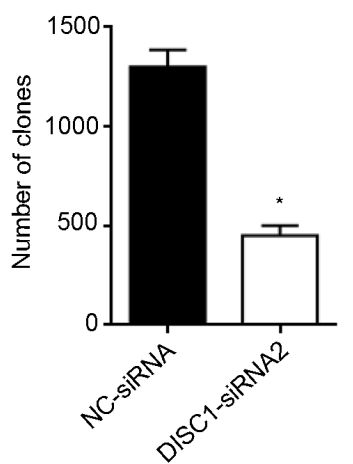

Figure 6: siRNA-mediated DISC1 silencing in NSCLC cells. DISC1 was silenced using siRNAs (DISC1-siRNA1, DISC1siRNA2 and DISC1-siRNA3) in A549 cells, as detected by western blotting (A) DISC1 knockdown by DISC1-siRNA1, DISC1-siRNA2, and DISC1-siRNA3 (B) PCNA and Cyclin D1 levels were detected by western blotting (C) DISC1-siRNA2-treated A549 cell proliferation as measured by CCK-8 assay (D) Colony formation by DISC1-siRNA2-treated A549 cells (E) The number of cell clones by DIC1-siRNA2treated A549 cells $(\mathbf{F}) * P<0.05$ compared NC-siRNA-treated cells.

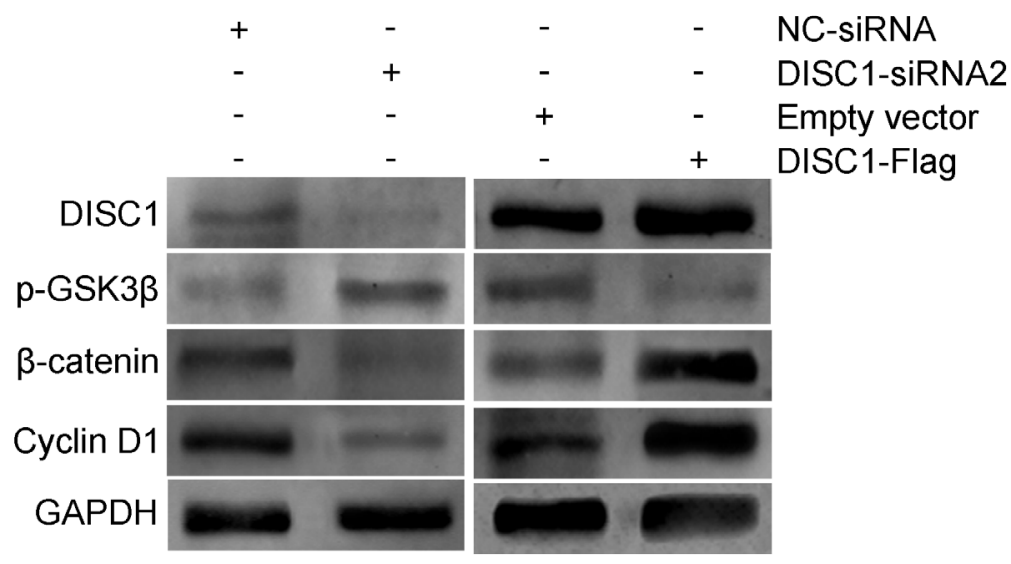

Figure 7: Effects of DISC1 expression on GSK3 $\beta / \beta$-catenin signaling in NSCLC cells. After DISC1 inhibition or upregulation in A549 cells using DISC1-siRNA2 or DISC1-Flag, respectively, DISC1, p-GSK3 $\beta, \beta$-catenin, and cyclin D1 were detected via western blotting. 
Table 4: DISC1-targeting siRNAs

\begin{tabular}{lcc}
\hline siRNA name & & Sequence (5'-3') \\
\hline DISC1-siRNA1 & Sense & GCUGAGACGUUACAACAAAdTdT \\
DISC1-siRNA2 & Antisense & UUUGUUGUAACGUCUCAGCdTdT \\
& Sense & GCCAUAUCAGGAAACCAUUdTdT \\
DISC1-siRNA3 & Antisense & AAUGGUUUCCUGAUAUGGCdTdT \\
& Sense & GGAAGCUUGUCGAUUGCUUdTdT \\
& Antisense & AAGCAAUCGACAAGCUUCCdTdT \\
\hline
\end{tabular}

that of p-GSK3 $\beta$, $\beta$-catenin, Cyclin D1, and Ki-67, and was associated with clinicopathologic variables. Cox's proportional hazards model indicated that DISC1 could be an independent prognostic factor for NSCLC patient survival, and Kaplan-Meier analysis showed that DISC1 overexpression predicted poor survival. Finally, a serum starvation and release assay indicated that DISC1 promoted A549 cell proliferation and might play a role in cell cycle progression.

Neurological studies reported that DISC1 directly interacts with GSK $3 \beta$, and suggested that GSK3 $\beta$ promotes $\beta$-catenin phosphorylation and ubiquitylation-mediated $\beta$-catenin degradation in the proteasome [16-19]. However, DISC1 inhibits GSK3 $\beta$ activity by reducing $\beta$-catenin phosphorylation and stabilizing $\beta$-catenin during brain development, which in turn activates transcription of $\beta$-catenin target genes, including Cyclin D1 [20]. Whether or not DISC1 activates $\mathrm{Wnt} / \beta$-catenin signaling through GSK3 $\beta$ inhibition in NSCLC remains unknown. Our results indicated that DISC1 might act as an oncogene in NSCLC development through Wnt/ $\beta$-catenin signaling, and high DISC1 expression correlated with decreased GSK3 $\beta$ phosphorylation. Additionally, DISC1 knockdown increased p-GSK3 $\beta$ expression and decreased that of $\beta$-catenin and Cyclin D1, while DISC1 upregulation produced the opposite results. In summary, we identified a novel role for DISC1 as a potential NSCLC oncogene. Our study suggests that DISC1 might promote NSCLC cell proliferation through GSK3 $\beta / \beta$-catenin signaling, and could be a novel antiNSCLC therapeutical target.

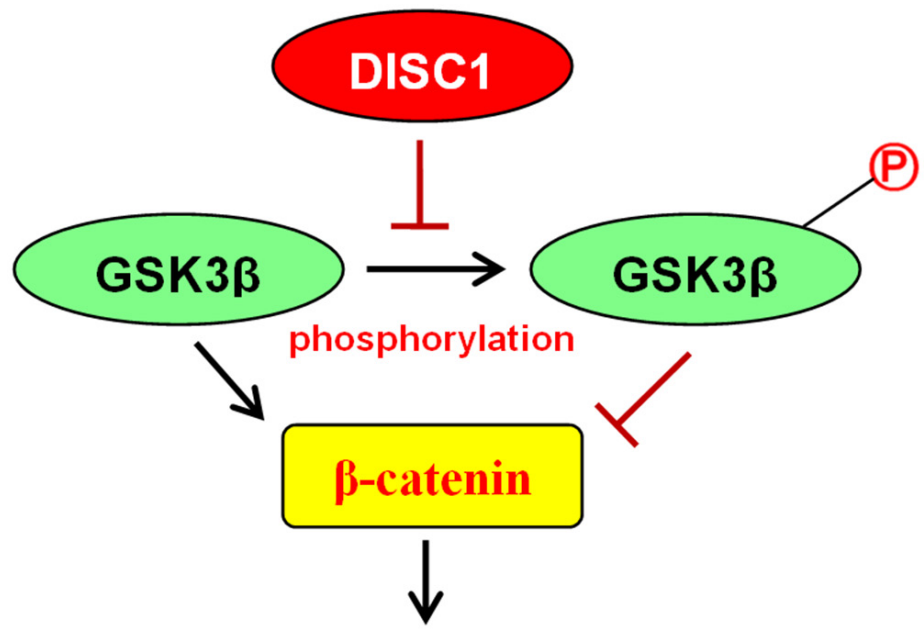

Cyclin D1

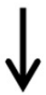

NSCLC cell growth

Figure 8: Hypothesized mechanism for DISC1 overexpression promotion of NSCLC cell proliferation. 


\section{MATERIALS AND METHODS}

\section{Patient tissue samples}

Eight paired NSCLC and adjacent non-tumor tissues were collected immediately after surgical removal and stored at $-80^{\circ} \mathrm{C}$ for western blot analysis. Additionally, 140 NSCLC specimens, along with patient demographic information and clinical data (Table 1), were obtained from the Department of Pathology, Affiliated Hospital of Nantong University between 2008 and 2013 for IHC analysis. Informed consent was obtained from all study participants. The Ethics Committee of the Affiliated Hospital of Nantong University provided permission to use tissue sections for research purposes.

\section{NSCLC cell lines and cultures}

NSCLC cell lines (A549, H1299, and SPCA-1) were obtained from the Institute of Cell Biology, Chinese Academy of Sciences. Cells were cultured in RPMI 1640 medium (Gibco, USA) containing 10\% fetal bovine serum (FBS) at $37^{\circ} \mathrm{C}$ with $5 \% \mathrm{CO}_{2}[23]$.

\section{Western blotting and immunohistochemistry}

Western blotting, and IHC analysis and evaluation were performed as described previously [23, 25-26]. Antibodies used were: anti-DISC1 (1:500 dilution; Santa Cruz Biotechnology, USA), anti-p-GSK3 $\beta$ (Tyr279/ Tyr216) (1:500 dilution; Santa Cruz Biotechnology), anti$\beta$-catenin (1:500 dilution; Santa Cruz Biotechnology), antiCyclin D1 (1:500 dilution; Santa Cruz Biotechnology), anti-PCNA (1:1000 dilution; Santa Cruz Biotechnology), and anti-GAPDH (1:3000 dilution; Sigma-Aldrich, USA).

\section{siRNAs, plasmid and transfection}

siRNAs targeting DISC1 and negative control siRNA (NC-siRNA) were purchased from GenePharma Co., Ltd (China) (Table 4), and a DISC1 over-expression plasmid (DISC1-Flag) (GeneCopoeia, China) was also used. siRNAs and plasmid were transfected into NSCLC cell lines using Lipofectamine 2000 (Life Technologies, USA) according to the manufacturer's instructions.

\section{Cell cycle assay}

A serum starvation and release process was used for cell cycle synchronization. Briefly, A549 cells were cultured in RPMI 1640 medium without FBS for $72 \mathrm{~h}$, and were then replaced by $10 \%$ FBS-supplemented medium. Cells were then fixed in $70 \%$ ethanol for $1 \mathrm{~h}$ at $4^{\circ} \mathrm{C}$ and incubated with $1 \mathrm{mg} / \mathrm{mL}$ RNaseA for $30 \mathrm{~min}$ at $37^{\circ} \mathrm{C}$. Cells were stained with propidium iodide (PI, $50 \mu \mathrm{g} / \mathrm{mL}$ ) (Becton Dickinson, USA) in PBS and $0.5 \%$ Triton X-100, and analyzed using a BD FACScan flow cytometer (Becton Dickinson, San Jose, USA) and the CellQuest acquisition and analysis program.

\section{Cell proliferation assay}

Cell counting kit-8 (CCK8) assay was performed to evaluate cell proliferation. A549 cells were seeded into 96well cell culture cluster plates (Corning, USA) at $2 \times 10^{4}$ cells/ well, cultured overnight, and then transfected with DISC1siRNA2 and negative control siRNA. CCK-8 reagents (Dojindo, Japan) were added to each well at different time points, and wells were incubated for an additional $2 \mathrm{~h}$ at $37^{\circ} \mathrm{C}$ in the dark. Absorbency was measured at $450 \mathrm{~nm}$ (reference $650 \mathrm{~nm}$ ) with a microplate reader (Bio-Rad, USA). Experiments were repeated at least three times.

\section{Colony formation assay}

Transfected A549 cells were seeded into 6-well cell culture cluster plates (Corning) at 200 cells/well, and incubated at $37^{\circ} \mathrm{C}$ with $5 \% \mathrm{CO}_{2}$ for $10 \mathrm{~d}$. Surviving colonies ( $>50$ cells/colony) were stained with $0.5 \%$ crystal violet and counted.

\section{Statistical analysis}

SPSS 19.0 software was used for statistical analysis. DISC1 expression and clinicopathological features were analyzed using the Chi-square $\left(\chi^{2}\right)$ test. Kaplan-Meier curves were constructed and Log-rank test was performed to analyze survival data. Multivariate analysis was performed using Cox's proportional hazards model. The risk ratio and its $95 \%$ confidence interval were recorded for each marker. $P<0.05$ was considered statistically significant. All values were expressed as means $\pm \mathrm{SD}$. Each experiment was repeated at least three times.

\section{ACKNOWLEDGMENTS}

The authors would like to thank Baoying Hu for her assistance.

\section{CONFLICTS OF INTEREST}

The authors declare no conflicts of interest.

\section{GRANT SUPPORT}

This study was supported by the National Natural Science Foundation of China (81501975), China Postdoctoral Science Foundation (2103M541705), University Science Research Project of Jiangsu Province (15KJB310013), Six Talent Peaks Project in Jiangsu Province (2014-YY-006), Jiangsu Province Postdoctoral Research Foundation (1301072C), Nantong Science and Technology Project (P), the Science Foundation of Nantong City, Jiangsu Province, China (HS2012025 and MS32015016) and Nantong University Innovation Project (YKC15087). 


\section{REFERENCES}

1. Cagle PT, Allen TC, Dacic S, Beasley MB, Borczuk AC, Chirieac LR, Laucirica R, Ro JY, Kerr KM. Revolution in lung cancer: new challenges for the surgical pathologist. Arch Pathol Lab Med. 2011; 135:110-116.

2. Sloan JA. Metrics to assess quality of life after management of early-stage lung cancer. Cancer J. 2011; 17:63-67.

3. Ulahannan SV, Brahmer JR. Antiangiogenic agents in combination with chemotherapy in patients with advanced non-small cell lung cancer. Cancer Invest. 2011; 29:325-337.

4. Ravdin PM, Davis G. Prognosis of patients with resected non-small cell lung cancer: impact of clinical and pathologic variables. Lung Cancer. 2006; 52:207-212.

5. Chubb JE, Bradshaw NJ, Soares DC, Porteous DJ, Millar JK. The DISC locus in psychiatric illness. Mol Psychiatry. 2008; 13:36-64.

6. Millar JK, Christie S, Semple CA, Porteous DJ. Chromosomal location and genomic structure of the human translin-associated factor X gene (TRAX; TSNAX) revealed by intergenic splicing to DISC1, a gene disrupted by a translocation segregating with schizophrenia. Genomics. 2000; 67:69-77.

7. Millar JK, Wilson-Annan JC, Anderson S, Christie S, Taylor MS, Semple CA, Devon RS, St Clair DM, Muir WJ, Blackwood DH, Porteous DJ. Disruption of two novel genes by a translocation co-segregating with schizophrenia. Hum Mol Genet. 2000; 9:1415-1423.

8. Millar JK, Christie S, Anderson S, Lawson D, Hsiao-Wei Loh D, Devon RS, Arveiler B, Muir WJ, Blackwood DH, Porteous DJ. Genomic structure and localisation within a linkage hotspot of Disrupted In Schizophrenia 1, a gene disrupted by a translocation segregating with schizophrenia. Mol Psychiatry. 2001; 6:173-178.

9. Brandon NJ, Sawa A. Linking neurodevelopmental and synaptic theories of mental illness through DISC1. Nat Rev Neurosci. 2011; 12:707-722.

10. Wang Q, Brandon NJ. Regulation of the cytoskeleton by Disrupted-in-schizophrenia 1 (DISC1). Mol Cell Neurosci. 2011; 48:359-364.

11. Brandon NJ, Millar JK, Korth C, Sive H, Singh KK, Sawa A. Understanding the role of DISC1 in psychiatric disease and during normal development. J Neurosci. 2009; 29:12768-12775.

12. Johnstone M, Thomson PA, Hall J, McIntosh AM, Lawrie SM, Porteous DJ. DISC1 in schizophrenia: genetic mouse models and human genomic imaging. Schizophr Bull. 2011; 37:14-20.

13. Mao Y, Ge X, Frank CL, Madison JM, Koehler AN, Doud MK, Tassa C, Berry EM, Soda T, Singh KK, Biechele T, Petryshen TL, Moon RT, Haggarty SJ, Tsai LH. Disrupted in schizophrenia 1 regulates neuronal progenitor proliferation via modulation of GSK3beta/beta-catenin signaling. Cell. 2009; 136:1017-1031.
14. Davidson G, Niehrs C. Emerging links between CDK cell cycle regulators and Wnt signaling. Trends Cell Biol. 2010; 20:453-460.

15. Liu C, Li Y, Semenov M, Han C, Baeg GH, Tan Y, Zhang Z, Lin X, He X. Control of beta-catenin phosphorylation/ degradation by a dual-kinase mechanism. Cell. 2002; 108:837-847.

16. Su Y, Fu C, Ishikawa S, Stella A, Kojima M, Shitoh K, Schreiber EM, Day BW, Liu B. APC is essential for targeting phosphorylated beta-catenin to the SCFbeta-TrCP ubiquitin ligase. Mol Cell. 2008; 32:652-661.

17. Ikeda S, Kishida S, Yamamoto H, Murai H, Koyama S, Kikuchi A. Axin, a negative regulator of the Wnt signaling pathway, forms a complex with GSK-3beta and beta-catenin and promotes GSK-3beta-dependent phosphorylation of beta-catenin. EMBO J. 1998; 17:1371-1384.

18. Zeng L, Fagotto F, Zhang T, Hsu W, Vasicek TJ, Perry WL 3rd, Lee JJ, Tilghman SM, Gumbiner BM, Costantini F. The mouse Fused locus encodes Axin, an inhibitor of the Wnt signaling pathway that regulates embryonic axis formation. Cell. 1997; 90:181-192.

19. Stewart DJ. Wnt signaling pathway in non-small cell lung cancer. J Natl Cancer Inst. 2014; 106:djt356.

20. Zhang Y, Zhang X, Huang J, Dong Q. Wnt signaling regulation of stem-like properties in human lung adenocarcinoma cell lines. Med Oncol. 2015; 32:157.

21. Xu X, Sun PL, Li JZ, Jheon S, Lee CT, Chung JH. Aberrant Wnt1/B-catenin expression is an independent poor prognostic marker of non-small cell lung cancer after surgery. J Thorac Oncol. 2011; 6:716-724.

22. Wan C, Hou S, Ni R, Lv L, Ding Z, Huang X, Hang Q, He S, Wang Y, Cheng C, Gu XX, Xu G, Shen A. MIF4G domain containing protein regulates cell cycle and hepatic carcinogenesis by antagonizing CDK2-dependent p27 stability. Oncogene. 2015; 34:237-245.

23. Liu K, Wang S, Liu Y, Gu J, Gu S, Xu Z, Zhang R, Wang Z, Ma H, Chen Y, Ji L. Overexpression of MYCN promotes proliferation of non-small cell lung cancer. Tumour Biol. 2016; 37:12855-12866.

24. Wang Y, Liu F, Mao F, Hang Q, Huang X, He S, Wang Y, Cheng $\mathrm{C}$, Wang $\mathrm{H}, \mathrm{Xu} \mathrm{G}$, Zhang $\mathrm{T}$, Shen $\mathrm{A}$. Interaction with cyclin $\mathrm{H} /$ cyclin-dependent kinase 7 (CCNH/CDK7) stabilizes C-terminal binding protein 2 (CtBP2) and promotes cancer cell migration. J Biol Chem. 2013; 288:9028-9034.

25. Wang S, Lu J, You Q, Huang H, Chen Y, Liu K. The $\mathrm{mTOR} / \mathrm{AP}-1 / \mathrm{VEGF}$ signaling pathway regulates vascular endothelial cell growth. Oncotarget. 2016; 7:53269-53276. doi: 10.18632/oncotarget.10756.

26. Wood SL, Pernemalm M, Crosbie PA, Whetton AD. The role of the tumor-microenvironment in lung cancermetastasis and its relationship to potential therapeutic targets. Cancer Treat Rev. 2014; 40:558-566. 